\title{
EXPRESSÃO DOS MARCADORES DE ANGIOGÊNESE FATOR VIII E CD- 34 NO ADENOCARCINOMA GÁSTRICO
}

\author{
Expression of angiogenesis markers Factor VIII and CD-34 in gastric \\ adenocarcinoma
}

\author{
Adriano Guimarães IBIAPINA, Osvaldo MALAFAIA, Jurandir Marcondes RIBAS-FILHO, \\ Nicolau Gregori CZECZKO, Ulrich Andreas DIETZ, \\ Marcelo Mazza do NASCIMENTO, Teresa Cristina Santos CAVALCANTI
}

ABCDDV/585

\begin{abstract}
Ibiapina AG, Malafaia O, Ribas-Filho JM, Czeczko NG, Dietz UA, Nascimento MM, Cavalcanti TCS.Expressão dos marcadores de angiogênese fator VIII e CD-34 no adenocarcinoma gástrico. ABCD Arq Bras Cir Dig 2008;21(1):25-32

RESUMO - Racional - O câncer gástrico continua sendo objeto de grande número de estudos que tentam entender melhor sua gênese, e conseqüentemente propor novos tratamentos. Na atualidade destaque especial está sendo dado na marcação imunoistoquímica onde estão sendo utilizados marcadores diversos sem se saber ainda qual ou quais são os mais efetivos no diagnóstico. Objetivo - Identificar e quantificar por citometria de imagem a expressão dos marcadores de angiogênese Fator VIII e CD-34 em tumores gástricos. Métodos - Foram utilizados 29 casos de adenocarcinomas gástricos, todos oriundos de material arquivado e conservado em blocos de parafina. Após a desparafinização, realizou-se coloração com marcadores imunoistoquímicos de angiogênese Fator VIII e CD-34, e as lâminas coradas foram submetidas a estudo citofotométrico de imagem em sistema informatizado SAMBA 4000. Resultados - Foram comparados os dois parâmetros oferecidos pelo método, índice de marcagem e densidade óptica, apenas nos 17 casos em que ocorreu identificação de ambos marcadores. Observou-se expressão numericamente significativa de ambos, porém o Fator VIII apresentou melhor média de densidade óptica, enquanto o CD-34 melhor resultado quanto ao índice de marcagem. Conclusão - A citometria de imagem foi capaz de identificar e quantificar a expressão do Fator VIII e CD-34 de maneira confiável e satisfatória demonstrando presença de angiogênese, sendo que o Fator VIII marcou menores áreas com melhor qualidade e o CD-34 marcou maiores áreas com menor qualidade.

DESCRITORES - Agentes moduladores da angiogênese. Fator VIII. Antígenos CD. Citometria por imagem. Neoplasias gástricas.
\end{abstract}

\section{INTRODUÇÃO}

O câncer de estômago tem grande importância em saúde pública e segundo o Hospital do Câncer Antônio Cândido de Camargo, figura ele como o mais freqüente do aparelho digestivo além de estar entre as três doenças neoplásicas malignas mais comuns no Brasil e no mundo. Ele ocorre predominantemente sob três variantes histológicas: adenocarcinoma (95\%), linfoma (3\%) e leiomiossarcoma em pequena incidência ${ }^{9}$. É mais freqüente no grupo masculino na proporção aproximada de dois homens para uma mulher, em geral acima dos 50 anos e com pico por volta do 70 anos.

Nos países desenvolvidos sua incidência tem diminuído, talvez por menor exposição aos fatores de risco, porém nos países em desenvolvimento, a exemplo do

Trabalho realizado no Instituto de Pesquisas Médicas do Hospital Universitário Evangélico de Curitiba / Faculdade Evangélica do Paraná. Curitiba - PR - Brasil

Correspondência: Adriano Guimarães Ibiapina - E-mail: ipem@evangelico.org.br
Brasil, mesmo com todos recursos médicos tecnológicos disponíveis sua prevalência tem-se mantido constante e, em algumas regiões mais pobres, até aumentado despertando preocupação e interesse de pesquisadores.

As pesquisas têm amplamente demonstrado que a dieta, hábitos e condições da vida influenciam claramente na carcinogênese gástrica, como alimentação pobre em vitaminas A e C, carnes e peixes, consumo excessivo de álcool, fumo, produtos enlatados, defumados, com corantes e conservantes ${ }^{11}$. O uso do sal como conservante tem sido considerado fator de risco, como também o alto consumo de nitratos. Soma-se a isto o papel do Helicobacter Pylori que induz inflamação persistente na mucosa gástrica ${ }^{13}$, sendo as cepas cagA e vacA responsáveis por processo inflamatório mais severo, aumentando o risco de úlcera péptica e câncer ${ }^{20}$.

As doenças malignas do estômago, particularmente o adenocarcinoma, têm sido objeto de estudo há muitos anos. Porém em nosso meio a doença continua sendo diagnosticada, em sua grande maioria, em estágio avançado, comprometendo o resultado do tratamento e piorando 
muito o prognóstico. Assim, qualquer estudo que vise criar ferramentas para sua detecção precoce merece destaque. $\mathrm{O}$ grande desafio da ciência moderna é promover a prevenção e a deteç̧ão precoce das afecções que ainda não apresentam tratamento curativo eficaz quando diagnosticado tardiamente.

A evolução do estudo da genética humana e da biologia molecular, com seus métodos modernos de detectar alterações genéticas congênitas ou falhas adquiridas que causam transtornos no ciclo de vida celular, vem suprir a lacuna existente e proporcionar novos horizontes tanto na prevenção quanto no diagnóstico e tratamento das afecções malignas. Conseqüentemente, tem influenciado o prognóstico dessas doenças. Prova disso é a descoberta de grande número de marcadores imunoistoquímicos de atividade celular e angiogênese, que vem dando novos rumos ao entendimento da carcinogênese e propondo novas hipóteses.

O estudo específico dos marcadores tumorais no adenocarcinoma de estômago visa criar protocolos para seu reconhecimento precoce, tendo vários autores demonstrado que suas expressões indicam com exatidão e segurança a presença do tumor. Este raciocínio leva a crer que na medida em que evoluam as pesquisas, possa-se associar a presença de determinado marcador em tecido sadio com possível grupo de risco e determinar rastreamento precoce e rigoroso, além de indicar tratamento e prognóstico em casos de doença maligna.

O uso de métodos citofotométricos de aferição computadorizada da expressão de marcadores, está conferindo alto grau de confiabilidade nos resultados, contribuindo para o avanço da pesquisa de combate ao câncer.

A angiogênese é a formação de novos vasos sanguíneos a partir dos já existentes, sendo reconhecida como evento fundamental para proliferação celular e naturalmente para carcinogênese primária e metastática, ocorrendo principalmente em adultos. O desenvolvimento de novos vasos sanguíneos obedece equilíbrio entre fatores naturais pró e anti-angiogênicos. Se a regulação deste equilíbrio é afetada, o que ocorre durante o crescimento tumoral, os vasos começam a formar-se em locais e momentos inadequados ${ }^{10}$.

A identificação da formação de novos vasos sanguíneos relaciona-se claramente ao aparecimento e a expansão de lesões malignas, logo, a descoberta de substâncias capazes de indicar a evolução deste processo passou a assumir importante papel no estudo do câncer. Os marcadores de angiogênese Fator VIII e CD-34 fazem parte de um grupo de substâncias que após reação imunoistoquímica, indicam o crescimento de novos vasos. Estes estudos tomam grande dimensão na medida em que propiciam não só o diagnóstico preciso, mas o desenvolvimento de drogas que atuem de forma seletiva na angiogênese tumoral.

O Fator VIII é uma glicoproteína adesiva de estrutura multimérica produzida exclusivamente por células endoteliais e megacariócitos ${ }^{15}$. Ele permite que as plaquetas fiquem aderidas à parede do vaso, formando uma ponte entre as fibrilas colágenas da parede vascular e receptores situados nas glicoproteínas plaquetárias, como se fossem amarrações entre uma embarcação e o ancoradouro ${ }^{6}$. A presença do Fator VIII indica área de adensamento plaquetário e por conseguinte vascular. Pode ser detectado imunoistoquimicamente usando-se o anticorpo anti-Fator VIII e fornece o grau de angiogênese, principalmente em áreas de metástase.

O CD-34 é uma glicoproteína expressa na superfície (membrana) das células progenitoras ou primitivas do sistema hematopoiético. Vale lembrar que o sistema hematopoiético é formado por células tronco, com capacidade de se diferenciar em células progenitoras de toda linhagem sanguínea ${ }^{8}$. Estas células dão origem ao neoendotélio do sistema hematopoiético, relacionado seletivamente com proliferação vascular. É detectado por método de ensaio imunoistoquímico com uso do anticorpo monoclonal anti-CD-34, e mensura a angiogênese ajudando a entender como ocorre a nutrição sanguínea em diversas eventos fisiológicos, inclusive no câncer.

Este trabalho tem por objetivos identificar e quantificar por citometria de imagem a expressão imunoistoquímica dos marcadores da angiogênese Fator VIII e CD-34 no adenocarcinoma do estômago.

\section{MÉTODOS}

Este estudo foi realizado no Instituto de Pesquisas Médicas (IPEM) do Programa de Pós-Graduação em Princípios da Cirurgia do Hospital Universitário Evangélico de Curitiba / Faculdade Evangélica do Paraná e no CITOLAB -Laboratório de Citologia e Histopatologia Ltda, da cidade de Curitiba e foi aprovado pelo Comitê de Ética em Pesquisa da Sociedade Evangélica Beneficente.

A amostra inicial consistiu de 60 blocos parafinados e fixados em formalina de peças advindas de gastrectomias com diagnóstico de adenocarcinoma, realizadas entre 1998 e 2006, provenientes dos serviços de patologia do Hospital Regional do Gama do Distrito Federal e do Hospital Dom Orione de Araguaina (Tocantins).

Cada amostra foi pré-selecionada de acordo com o estado de conservação, confecção e que representavam melhor a massa tumoral, sendo submetidas à nova microtomia com espessura de cinco micra, coradas pela técnica de hematoxilina-eosina (HE) e apreciadas por dois patologistas experientes que confirmaram os diagnósticos. Foram incluídas amostras com confirmação de adenocarcinoma gástrico e excluídas as que não apresentavam concordância com o diagnóstico e as com material inadequado - tecido necrosado, fixação inadequada, formol não tamponado, tecido dobrado ou com sobreposição.

O método para obtenção da coloração imunoistoquímica foi o correntemente utilizado no CITOLAB.

O preparo incluiu duas etapas em dois dias. A primeira foi a desparafinização seguida de recuperação antigênica, bloqueio da peroxidase endógena e incubação das lâminas com anticorpo primário por toda a noite.

No segundo dia fez-se a incubação do anticorpo secundário (biotina) por 30 minutos (cor amarela) e após banho em solução tampão a incubação com streptovidina 
por mais 30 minutos (cor vermelha).

A seguir, as lâminas receberam a diaminobenzidina - DAB que, após ligar-se à streptovidina na árvore da reação, confere a coloração acastanhada. A streptovidina permanece ligada a biotina (anticorpo secundário), que por sua vez fica ligada ao primário. Esta reação fornece as cores a serem estudadas pelo sistema computadorizado. Faz-se ainda nova coloração com hematoxilina para fazer contraste com o fundo da lâmina, melhorando assim a visualização. Só então se prepara a montagem final para leitura no SAMBA, com sua identificação e etiquetagem.

Neste estudo foram utilizados os marcadores para Fator VIII e CD-34, que através de reação imunológica com anticorpo específico coram a angiogênese. Foi utilizado anticorpo anti-Fator VIII derivado de plasma de camundongo e anti-CD-34, tipo IgG, derivado de plasma de rato na concentração de $200 \mu / \mathrm{mL}$ (clone QBEnd/10 lab-vision).

Para aferição citofotométrica da imagem foi utilizado o sistema SAMBA 4000 - Systéme d'analyse microscopique á balayage automatique (Sistema de Análise Microscópica de Busca Automática) -, desenvolvido pela Alcatel (Grenoble, França), constituído por um hardware, capaz de captar com precisão as imagens microscópicas, e por um software que interpreta as imagens captadas e fornece os resultados. O equipamento é composto de microscópio óptico, câmera de vídeo, microcomputador, impressora e dois monitores (Figura 1).

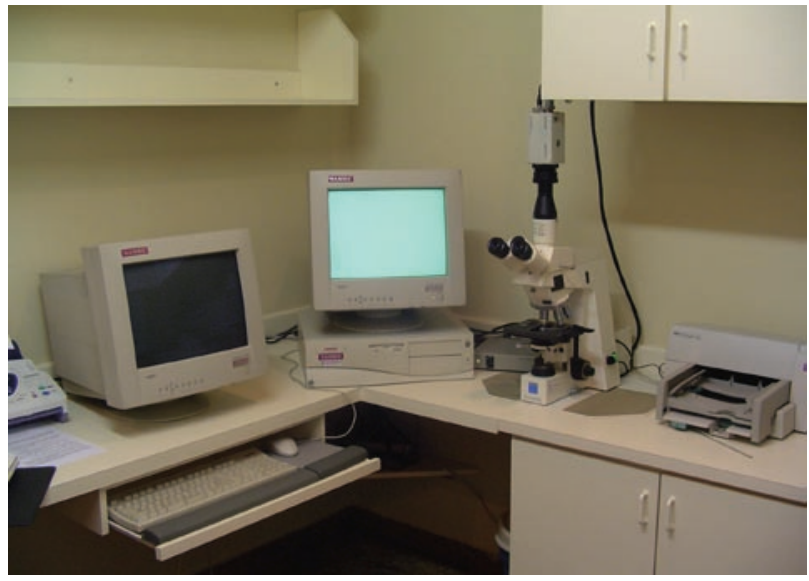

FIGURA 1 - Fotografia do equipamento de citometria de imagem

O programa de informática utilizado foi o Imunno 4.00 - versão 2.0 que em conjunto com o sistema SAMBA 4000, capta, processa e digitaliza a imagem das lâminas coradas, transformando as imagens analógicas em números e ainda identificando, selecionando e analisando o objeto do estudo, para então apresentar os resultados.

O funcionamento do sistema baseia-se na quantificação da luz absorvida pelo tecido em cada segmento estudado. Esta quantidade de luz captada por área, estimula o pontoimagem ou pixel, que assume tonalidade de cinza representando um valor que varia de zero (preto) a 255 (branco). A imagem analógica captada é processada e transformada em uma matriz numérica, distribuída em toda lâmina de acordo com a densidade da reação imunológica em cada área, representada por tons variados de cinza. Este processo permite a conversão de cor em número, ou seja, binarização da cor. Assim, onde a luz passou com maior ou menor intensidade, estimulou-se o pixel, que de acordo com a quantidade de luz captada e o tom de cinza obtido, fornece um valor numérico de zero a 255 (Figura 2).

0000000000000000000000000000000000000000000000000000000000000000000 000000000000000252051453625510000000000000000000000000000000000 00000000000026354161781052531422500000000000000000000000000000 0000000000003554324102200203200203500000000000000000000000000 0000000000035238117869578105141204350000000000000000000000000 0000000000023961183549469276664526000000000000000000000000000 00000000000000101765566859436482540000000000000000000000000000 00000000000000000011000001180020016000000000000000000015425689 0000000000000000000000000000000000000000000000000000000000000000000

FIGURA 2 - Ilustração do método de numerização da imagem pelo software: 0 (zero) equivale aos campos sem densidade; representação numérica da intensidade de luz que varia de acordo com a densidade do ponto estudado do tecido

A leitura de cada lâmina seguiu a metodologia preconizada por Brugal et al. ${ }^{1}$, que faz rastreamento dos campos visuais realizando a leitura em barra grega.

Ao se iniciar o uso do equipamento, procede-se calibragem do sistema SAMBA 4000, que consiste em três etapas. A primeira, é relacionada ao controle da luminosidade que incide na lâmina; a segunda, é realizada com lente objetiva de 100 vezes, procurando-se campos na lâmina para realizar o white-balance; a terceira é a calibragem feita no primeiro campo lido.

\section{Parâmetros avaliados pelo sistema SAMBA 4000}

O programa Imunno foi utilizado para quantificar a cor captada, avaliando-as em duas variáveis: índice de marcagem e densidade óptica média.

O índice de marcagem é demonstrado considerando a quantidade da área tecidual que foi corada em relação ao total de cada lâmina e expresso em porcentagem, indicando quantidade de marcação.

A densidade óptica avalia a quantidade de cor por área avaliada, demonstrando que áreas da lâmina com maior densidade de cor, apresentam maior densidade óptica da reação imunológica e conseqüentemente, maior expressão do marcador utilizado.

Estes parâmetros são automaticamente analisados e leva em consideração as duas variáveis selecionadas, cruza os dados e fornece resultado numérico expressos por médias, medianas, valores mínimos, valores máximos e desvios-padrão. A avaliação da condição de normalidade das variáveis foi feita pelo teste de Shapiro-Wilks. A comparação dos marcadores foi feita usando-se o teste $t$ de Student para amostras dependentes. A comparação entre dois grupos independentes de pacientes foi feita usando-se o teste não paramétrico de Mann-Whitney. Para avaliar a correlação entre marcadores estimou-se o coeficiente de correlação de Pearson. Valores de $P<0,05$ indicaram significância. 


\section{RESULTADOS}

Foram selecionados inicialmente 60 blocos que preenchiam os critérios para estudo, ou seja, de serem adenocarcinoma gástrico; no entanto, apenas 55 foram confirmados após novo estudo com HE e enviados para estudo imunoistoquímico. Dos 55, somente 35 tiveram condições técnicas de serem submetidos aos testes imunoistoquímicos e aptas para leitura no SAMBA.

Após preparadas, as lâminas foram submetidas à análise pelo sistema SAMBA, onde seis tiveram de ser descartadas por não apresentarem boa reação. $O$ total final foi de 29 para leitura citofotométrica da expressão do marcador CD-34 (Figura 3) e Fator VIII (Figura 4), sendo que em 22 casos houve expressão do Fator VIII e 26 casos expressaram o marcador CD-34. A leitura concomitante dos dois marcadores ocorreu em 17 lâminas, que serviram de base para as considerações mais significativas deste trabalho.

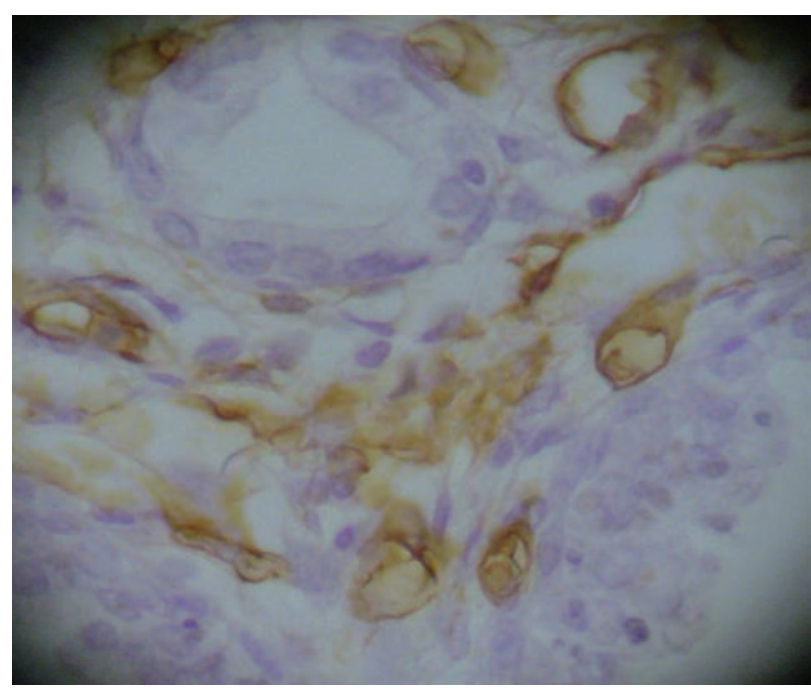

FIGURA 3 - Fotomicrografia da expressão CD-34 no adenocarcinoma gástrico

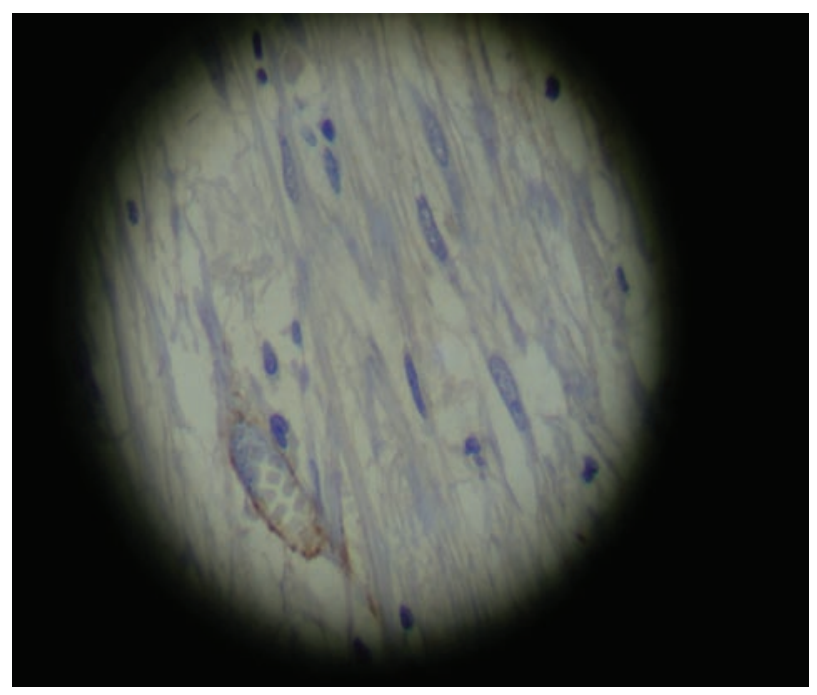

FIGURA 4 - Fotomicrografia da expressão do Fator VIII no adenocarcinoma gástrico

\section{Citofotometria do Fator VIII e CD-34}

A análise da Tabela 1 mostra que, com o Fator VIII, 22 casos foram adequadamente marcados e lidos nos dois parâmetros. O maior índice de marcagem foi de $75,71 \%$ e o menor de $29,16 \%$, com média de $63,11 \%$ e mediana de $70,18 \%$. Já a densidade óptica variou entre 72,73 e 46,37, com média de 61,83 e mediana aferida de 62,49.

TABELA 1 - Resultados da expressão do Fator VIII nos casos em que foi possível leitura $(n=22)$

\begin{tabular}{|c|c|c|c|c|}
\hline Campos lidos & Código casos & $\begin{array}{l}\text { Indice de } \\
\text { marcagem }\end{array}$ & $\begin{array}{c}\text { Densidade } \\
\text { óptica }\end{array}$ & $\mathbf{n}$ \\
\hline 10 & A2 & $72,61 \%$ & 69,63 & 1 \\
\hline 10 & $\mathrm{~A} 3$ & $52,94 \%$ & 62,36 & 2 \\
\hline 2 & A4 & $74,11 \%$ & 60,29 & 3 \\
\hline 10 & A5 & $75,71 \%$ & 62,72 & 4 \\
\hline 10 & A6 & $72,81 \%$ & 69,89 & 5 \\
\hline 10 & A7 & $71,92 \%$ & 6172 & 6 \\
\hline 10 & A9 & $57,50 \%$ & 63,62 & 7 \\
\hline 10 & A10 & $67,18 \%$ & 61,99 & 8 \\
\hline 10 & A12 & $71,21 \%$ & 72,73 & 9 \\
\hline 10 & A13 & $71,20 \%$ & 67,34 & 10 \\
\hline 10 & A15 & $71,33 \%$ & 65,71 & 11 \\
\hline 10 & A17 & $59,89 \%$ & 56,35 & 12 \\
\hline 10 & A18 & $69,15 \%$ & 71,27 & 13 \\
\hline 10 & A19 & $73,91 \%$ & 67,19 & 14 \\
\hline 10 & A20 & $72,10 \%$ & 67,44 & 15 \\
\hline 10 & A21 & $72,12 \%$ & 62,61 & 16 \\
\hline 10 & A22 & $61,75 \%$ & 60,93 & 17 \\
\hline 10 & A24 & $48,87 \%$ & 51,29 & 18 \\
\hline 10 & A25 & $50,79 \%$ & 55,6 & 19 \\
\hline 10 & A26 & $40,55 \%$ & 46,37 & 20 \\
\hline 10 & $\mathrm{~A} 30$ & $51,66 \%$ & 54,43 & 21 \\
\hline 10 & A37 & $29,16 \%$ & 48,68 & 22 \\
\hline
\end{tabular}

A Tabela 2 detalha a marcação do CD-34 em 26 casos, e também cita a densidade óptica e o índice de marcagem em cada lâmina, mostrando que nesses casos, o índice de marcagem variou de $97,56 \%$ a $57,51 \%$, com média de $84,86 \%$ e mediana de $85,76 \%$, enquanto a densidade óptica oscilou entre 66,64 e 34,11, com média aferida de 49,84 e mediana de 50,09.

\section{Correlação entre os marcadores}

Em relação ao índice de marcagem, o coeficiente de correlação estimado entre o Fator VIII e o do CD-34 foi igual a $-0,271$. Testou-se a hipótese nula de que não existia correlação entre estes dois índices, versus a alternativa de que ela existia. O resultado do teste indicou nulidade na correlação $(P=0,293)$. Sendo assim, nos 17 pacientes em que houve a expressão de ambos os marcadores, não se pode afirmar que, entre eles, existe correlação significativa (Tabela 3). 
TABELA 2 - Resultados da expressão do CD-34 nos casos em que foi possível a leitura $(\mathrm{n}=26)$

\begin{tabular}{ccccc}
\hline Campos lidos & Código & $\begin{array}{c}\text { Indice de } \\
\text { marcagem }\end{array}$ & $\begin{array}{c}\text { Densidade } \\
\text { óptica }\end{array}$ & n \\
\hline 10 & A2 & $71,58 \%$ & 45,13 & 1 \\
10 & A3 & $90,42 \%$ & 54,18 & 2 \\
10 & A6 & $78,96 \%$ & 56,47 & 3 \\
10 & A7 & $57,51 \%$ & 42,76 & 4 \\
10 & A9 & $84,57 \%$ & 57,36 & 5 \\
10 & A10 & $85,56 \%$ & 44,24 & 6 \\
10 & A12 & $87,41 \%$ & 49,82 & 7 \\
10 & A13 & $80,53 \%$ & 34,11 & 8 \\
10 & A14 & $89,98 \%$ & 50,35 & 9 \\
10 & A15 & $71,69 \%$ & 34,13 & 10 \\
10 & A17 & $84,78 \%$ & 46,01 & 11 \\
10 & A18 & $94,78 \%$ & 64,11 & 12 \\
10 & A21 & $97,56 \%$ & 53,62 & 13 \\
10 & A22 & $86,82 \%$ & 46,52 & 14 \\
10 & A24 & $94,44 \%$ & 48,73 & 15 \\
10 & A25 & $77,39 \%$ & 63,56 & 16 \\
10 & A26 & $81,70 \%$ & 40,21 & 17 \\
10 & A27 & $82,28 \%$ & 45,08 & 18 \\
10 & A28 & $85,95 \%$ & 50,57 & 19 \\
10 & A29 & $91,61 \%$ & 66,64 & 20 \\
10 & A30 & $87,43 \%$ & 47,52 & 21 \\
10 & A31 & $84,34 \%$ & 50,43 & 22 \\
10 & A32 & $94,02 \%$ & 57,48 & 23 \\
10 & A35 & $95,94 \%$ & 57,38 & 24 \\
10 & A36 & $94,57 \%$ & 50,71 & 25 \\
10 & A38 & $74,57 \%$ & 38,6 & 26 \\
\hline & & & & \\
\hline
\end{tabular}

TABELA 3 - Correlação entre os marcadores Fator VIII e CD34

\begin{tabular}{lccc}
\hline Parâmetros & n & $\begin{array}{c}\text { Coeficiente de cor- } \\
\text { relação de Pearson }\end{array}$ & Valor de $\boldsymbol{P}$ \\
\hline $\begin{array}{l}\text { Índice de marcagem do Fator VIII x índice } \\
\text { de marcagem do CD-34 }\end{array}$ & 17 & $-0,271$ & 0,293 \\
$\begin{array}{l}\text { Densidade óptica do CD-34 x densidade } \\
\text { óptica do Fator VIII }\end{array}$ & 17 & 0,139 & 0,598 \\
$\begin{array}{l}\text { Densidade óptica do CD-34 x índice de } \\
\text { marcagem do CD-34 }\end{array}$ & 17 & 0,413 & 0,100 \\
$\begin{array}{l}\text { Densidade óptica do Fator VIII x índice de } \\
\text { marcagem do Fator VIII }\end{array}$ & 17 & 0,859 & $<\mathbf{0 , 0 0 1}$ \\
\hline
\end{tabular}

Em relação à densidade óptica, o coeficiente de correlação estimado de ambos foi igual a 0,139 . Testou-se a hipótese nula de que não existia correlação entre os dois marcadores, versus a alternativa de que ela existia. O resultado indicou nulidade na correlação $(P=0,598)$. Assim, nos 17 pacientes com expressão de ambos os marcadores, não se pode afirmar que existe correlação significativa entre a densidade óptica do CD-34 e a do Fator VIII (Tabela 3).

A correlação entre a densidade óptica e índice de marcagem no CD-34, o coeficiente de correlação estimado foi igual a 0,413. Testou-se a hipótese nula de que não existia correlação entre estes dois marcadores, versus a alternativa de que ela existia. $\mathrm{O}$ resultado indicou nulidade na correlação $(P=0,1)$. Logo, nos 17 pacientes com expressão de ambos os marcadores, não se pode afirmar que existe correlação significativa entre a densidade ótica e índice de marcagem do CD-34 ( Tabela 3).
Na correlação entre a densidade óptica e o índice de marcagem no Fator VIII, o coeficiente estimado foi igual a 0,859 . Testou-se a hipótese nula de que não existia correlação entre estes dois marcadores, versus a alternativa de que ela existia. $\mathrm{O}$ resultado indicou a não rejeição da nulidade $(P<0,001)$. Sendo assim, nos 17 pacientes com expressão de ambos os marcadores, pode-se afirmar que existe correlação significativa entre a densidade óptica e índice de marcagem do Fator VIII (Tabela 3).

Na comparação entre a média de marcação, mediana, valores mínimo e máximo, desvios-padrão dos marcadores, a análise em que testou-se a hipótese nula de que as médias do índice de marcagem são iguais para os marcadores CD34 e Fator VIII, versus a hipótese alternativa de que as médias são diferentes, rejeitou a hipótese nula $(P<0,001)$. Sendo assim, conclui-se que existe diferença significativa entre os marcadores CD-34 e Fator VIII em relação à média do índice de marcagem. Na Tabela 4 observa-se que a média do CD-34 é maior do que a do Fator VIII.

TABELA 4 - Comparação entre os índices de marcagem do CD34 e do Fator VIII

\begin{tabular}{lccccccc}
\hline Marcador & n & Média & Mediana & Mínimo & Máximo & $\begin{array}{c}\text { Desvio } \\
\text { padrão }\end{array}$ & $\begin{array}{c}\text { Valor } \\
\text { de } \boldsymbol{P}^{*}\end{array}$ \\
\hline CD-34 & 17 & 83,13 & 84,78 & 57,51 & 97,56 & 9,89 & \\
Fator VIII & 17 & 62,56 & 67,18 & 40,55 & 72,81 & 10,40 & \\
$\begin{array}{l}\text { Diferença (Fator VIII } \\
- \text { CD-34) }\end{array}$ & 17 & $-20,57$ & $-25,07$ & $-45,57$ & 14,41 & 16,18 & $<0,001$ \\
\hline
\end{tabular}

$\left(^{*}\right)$ Teste $t$ de Student para amostras pareadas $(P<0,05)$

Quanto à densidade óptica, na análise testou-se a hipótese nula de que ela é igual para ambos, versus a hipótese alternativa de que seria diferente. Na Tabela 5 são apresentados os valores de média, mediana, mínimo, máximo e desvios-padrão do índice de marcagem dos dois marcadores.

TABELA 5 - Comparação entre as densidades ópticas do Fator VIII e CD-34

\begin{tabular}{lccccccc}
\hline Marcador & n & Média & Mediana & Mínimo & Máximo & $\begin{array}{c}\text { Desvio } \\
\text { padrão }\end{array}$ & $\begin{array}{c}\text { Valor } \\
\text { de } \boldsymbol{P}^{*}\end{array}$ \\
\hline CD-34 & 17 & 48,73 & 47,52 & 34,11 & 64,11 & 8,76 & \\
Fator VIII & 17 & 61,99 & 62,36 & 46,37 & 72,73 & 7,32 & \\
$\begin{array}{l}\text { Diferença (Fator VIII } \\
\text { - CD-34) }\end{array}$ & 17 & 13,26 & 10,34 & $-7,96$ & 33,23 & 10,61 & $<0,001$ \\
\hline
\end{tabular}

O resultado do teste estatístico indicou a rejeição da hipótese nula $(P<0,001)$. Sendo assim, conclui-se que existe diferença significativa entre os marcadores CD-34 e Fator VIII em relação à densidade óptica. Na Tabela 5 observa-se que a média do Fator VIII é superior a do CD-34.

\section{DISCUSSÃO}

Considerando-se a dificuldade na obtenção de material, não foram utilizadas peças frescas neste estudo e sim, material parafinado oriundo de arquivos dos quais não se teve conhecimento dos meios de confecção e armazenamento 
na origem. Estes fatos contribuíram para a queda na qualidade da amostra que teve drop-out grande. Assim, embora não inviabilizando estudos, cuidado redobrado deve se ter quando são usados casos oriundos de material de arquivo de laboratórios de histopatologia sem padronização de técnica.

Apenas 35 blocos foram encaminhados para imunoistoquímica e sistema SAMBA, revelando perda de 51,66\% das amostras. Ela pode ser considerada alta, mas justifica-se pelo rigor da seleção e preocupação de ser estudado apenas material com condições ideais.

A utilização da tecnologia avançada a serviço da ciência vem ocorrendo há muito. Neste caso a substituição do olho humano por um conjunto de equipamentos - hardware e software -, são capazes de identificar estruturas microscópicas com rapidez e precisão, ajudando no diagnóstico. Não implica apenas em trocar olho humano por um equipamento, pois não exclui o ser humano do processo, uma vez que o aparelho precisa ser regulado e calibrado para cada estudo, o que só pode ser realizado por profissional habilitado. Além do mais, as novas técnicas vem para ajudar e não substituir o homem. Já foi citado que $80 \%$ das peças histológicas de um laboratório de patologia podem ser diagnosticadas por patologista de forma segura quanto à malignidade e outros parâmetros, porém ocorrem dúvidas em $20 \%$. São nesses $20 \%$ que a citometria de imagem apresenta sua importância, pois ajuda a esclarecer o diagnóstico, na medida em que retira a subjetividade da interpretação morfológica do patologista.

O software usado foi o Imuno 4.00 que consegue ler parâmetros de índice de marcagem e densidade óptica. Esta tecnologia apresenta bons resultados na literatura em tumores tireoidianos, de bexiga, de mama e na gravide $z^{21}$. Ele encontra-se disponível no IPEM desde 1994. Suas bases são lógicas e objetivas e promove ganho na compreensão do comportamento tumoral e auxílio na escolha da conduta mais apropriada ao paciente.

Como já é sabido, o Fator VIII endotelial é uma glicoproteina que age como cola entre as plaquetas e a parede dos vasos $^{15}$, e além de atuar na adesão e agregação plaquetária, participa como transportador do Fator VIII de coagulação de origem hepática e, sendo detectado por estudo imunoistoquímico, identifica área em que há plaquetas e vasos, por isso é considerado bom marcador de angiogênese ${ }^{17}$. O CD-34 também é marcador de angiogênese, uma vez que via anticorpo anti-CD-34, marca imunoistoquimicamente células CD-34 +, envolvidas no processo de replicação do endotélio vascular ${ }^{8}$. Assim, é licito pensar que qualquer estudo sobre angiogênese deve considerar a utilização desses marcadores a fim de mensurar-se a densidade microvascular.

Também já é sabido que a angiogênese é fenômeno fisiológico importante para manutenção da vida ${ }^{12}$, e processo indispensável para tumorigênese ${ }^{5}$. A identificação desses marcadores tem ajudado muito a diferenciar lesões benignas de malignas com maior segurança e orientar tratamento adequado.

Outro aspecto relevante que justifica o uso de mar- cadores de aferição da densidade microvascular, é a possibilidade do emprego de drogas antiangiogênicas na terapia do câncer experimental mostrando a eficácia em deter o avanço tumoral e de metástases induzidas onde, observando-se o CD-34, podia-se calcular a diminuição da densidade vascular local ${ }^{7,14,16}$.

No caso do Fator VIII, houve reconhecimento da expressão do marcador pelo sistema SAMBA em 22 casos, demonstrando que em 75,86\% das lâminas foi possível confirmar a angiogênese por meio dele. O Fator VIII é considerado pela literatura como padrão-ouro para detecção e aferição da densidade microvascular, quando comparado a outros marcadores de angiogênese. Alguns autores já mostraram relação de sua expressão com prognóstico de tumores diversos ${ }^{2,22}$.

O sistema SAMBA 4000, foi capaz de reconhecer a expressão do Fator VIII, em 75,86\% das lâminas estudadas, demonstrando alta densidade microvascular. Este resultado era esperado uma vez que o adenocarcinoma gástrico foi o material utilizado neste estudo e a angiogênese faz parte ativa dos seus eventos tumorigênicos ${ }^{4}$.

Alguns autores comprovaram ser a maior expressão do Fator VIII indicativa de pior prognóstico ${ }^{3,18}$. Devido à situação de alta densidade de Fator VIII aferida neste trabalho, não seria exagero sugerir que os casos estudados representavam estágios de doença mais avançados, e consequentemente com pior prognóstico.

Com certeza próximos estudos deverão comparar a densidade microvascular aferida por este marcador com as características clinico-patológicas desses tumores, e confirmarem a possível relação direta da intensidade de marcação com a fase mais avançada da doença aqui sugerida.

O CD-34, também avaliado nos mesmos parâmetros, mostrou bom desempenho e sua utilidade na detecção da angiogênese.

É fato que também com CD-34, houve boa coloração dos vasos, porém com densidade óptica ligeiramente inferior na média. Esta situação sugere que o CD-34 marcou maior número de vasos por lâmina, porém onde o Fator VIII marcou, corou com maior densidade e naturalmente com maior qualidade.

Ambos os marcadores foram detectados em 17 lâminas, o que reforça a tese que nelas a angiogenêse pôde ser facilmente demonstrada.

$\mathrm{O}$ estudo estatístico aqui realizado visou demonstrar matematicamente a possível relação entre os resultados obtidos entre o CD-34 e Fator VIII. Considerando-se apenas os 17 casos em que houve marcação de ambos, não foi possível correlacionar a quantidade com a qualidade dos vasos corados pelo CD-34. Também não foi possível encontrar correlação entre a quantidade de marcação do CD-34 com a do Fator VIII, nem detectou-se correlação estatisticamente aceitável entre a qualidade da cor marcada pelo CD-34 e Fator VIII,

$\mathrm{O}$ fato de não se poder estabelecer as correlações acima descritas não invalida a percepção de que são bons marcadores, pois a literatura os consagra ${ }^{19}$. Talvez em séries com maior número de casos possa ser estabelecida melhor cor- 
relação, ficando esta como sugestão para novos estudos.

A diferença existente neste trabalho entre os marcadores não permite julgar qual seria o melhor marcador para angiogênese, porém permite imaginar que o CD-34 seja menos seletivo para angiogênese que o Fator VIII. No mesmo tecido onde ambos foram aplicados, foi maior a expressão do CD-34, contudo com qualidade de marcação inferior a do Fator VIII.

Não restam dúvidas acerca da qualidade dos marcadores de angiogênese ora estudados, haja vista farta literatura que os ampara. Parece interessante e justo pensar que eles se complementam e, como ficou evidenciado neste trabalho, ambos marcam bem a angiogênese, todavia com características diferentes.

Assim, em qualquer trabalho que vise estudar a angiogênese é imperioso considerar a utilização desses marcadores.

\section{CONCLUSÃO}

A citometria de imagem foi capaz de identificar e quantificar a expressão do Fator VIII e CD-34 de maneira confiável e satisfatória demonstrando presença de angiogênese, sendo que o Fator VIII marcou menores áreas com melhor qualidade e o CD-34 marcou maiores áreas com menor qualidade.

Ibiapina AG, Malafaia O, Ribas-Filho JM, Czeczko NG, Dietz UA, Nascimento MM, Cavalcanti TCS. Expression of angiogenesis markers Factor VIII and CD-34 in gastric adenocarcinoma. ABCD Arq Bras Cir Dig 2008;21(1):25-32.

ABSTRACT - Background - Gastric cancer remains a subject of great interest in several studies searching for understanding its genesis and, therefore, proposing new treatments. Currently special credits have been given to immunohistochemistry as various markers are being tested with uncertain efficacy on diagnosis. Aim - To identify and quantify the expression of Factor VIII and CD-34, angiogenesis markers, in gastric tumors by imaging cytometry. Methods - Twenty-nine 29 gastric adenocarcinomas sampled-tissue in paraffin blocks underwent immunohistochemical angiogenesis markers evaluation for factor VIII and CD-34 and the marked slides were submitted to SAMBA 4000 reading. Results - The investigation method offered two comparison parameters, marking index and optical density, showing up both in 17 cases. Significant numerical expression had been observed for both markers, but Factor VIII showed a better optical density average while CD-34 presented a better result for marking index. Conclusion - Image cytometry identified and quantified Factor VIII and CD-34 expressions in a reliable and satisfactory manner, revealing the presence of angiogenesis. Factor VIII enhanced in smaller areas with better quality while CD-34 enhanced greater areas with lower quality.

HEADINGS - Angiogenesis modulating agents. Factor VIII. CD Antigens. Image cytometry. Gastric neoplasms.

\section{REFERÊNCIAS}

1. Brugal G, Chassery JM. Un nouveau système d'analyse densitométrique et morphologique des préparations microscopiques. Histochem. $1977 ; 52: 241$ 58.

2. Du JR, Jiang Y, Zhang YM, Fu H. Vascular endothelial growth factor and microvascular density in esophageal and gastric carcinoma. World J Gastroenterol. 2003;9(7):1604-6

3. Erenoglu C, Akin ML, Uluutku H, Tezcan L, Yildirim S, Batkin A. Angiogenesis predicts poor prognosis in gastric carcinoma. Dig Surg. 2000;17:581-6.

4. Folkman J. Role of angiogenesis in tumor growth and metastasis. Semin Oncol. 2002;6(suppl.16):15-8.

5. Gimbrone Jr. MA, Leapman SB, Cotran RS, Folkman J. Tumor dormancy in vivo by prevention of neovascularization. J Exp Med. 1972;136:261-76.

6. Girma JP, Meyer D, Verweij CL, Pannekoek H, Sixma JJ. Structure-function relationship of human von Willebrand factor. Blood 1987;70(3):605-11.

7. Griffin RJ, Williams BW, Wild R, Cherrington JM, Park H, Song CW. Simultaneos inhibition of the receptor kinase activity of vascular endothelial, fibroblast, and platelet-derived growth factors suppresses tumor growth and enhances tumor radiation response. Cancer Res. 2002;62(2):1702-6.

8. Grotto HZW, Noronha JF. Identificação de células tronco hematopoieticas: citometria de fluxo convencional versus contador hematológico automatizado. Rev Bras Hematol Hemoter. 2003;25(3):1-6.

9. INCA. http://www.inca.org.br/cancergastrico. Acesso em 14 de julho de 2006 , 17:00Hs.

10. Jain RK, Carmeliet PF. Vessels of death or life. Sci Am. 2001;285(6):38-45.

11. Kassabi P, Leme PLS. Epidemiologia do câncer gástrico. Rev Assoc Med Bras. $2003 ; 49(3): 1-3$.
12. Kwon M, Libutti SK. Advances in understanding angiogenesis trough molecular studies. International journal of radiation oncology. Biology, Physics 2006;64:26-32.

13. Ladeira MSP, Salvadori DMF, Marchesan MS. Biopatologia do Helicobacter pylori. J Bras Patol Med Lab. 2003;39(4):335-42.

14. Laird AD, Vajkoczy P, Thurnher A, Liang C, Mohammadi M, Achlessinger J, Ullrich A, Hubbard SR, Blake RA, Fong AT, Straw LM, Sun L, Tang C, Hawtin R, Tang F, Shenoy N, Hirth KP, McMahon G, Cherrington A. SU6668 is a potent antiangiogenic and antitumor agent that induces regression of estabilished tumors. Cancer Res. 2000;60(15):4150-52.

15. Lopes AAB, Maeda NY, Bydlowski SP. Fator von Willebrand e disfunção endotelial pulmonar. Implicações prognosticas. Arq Bras Cardiol. 1998;70(3):17.

16. Lu H, Lin C, Zheng Z, Li S, Guo S, Zhang X, Fu M, Liang X, Wu M. Angiogenesis inhibitor Z24 induces endothelial cell apoptosis and suppresses tumor growth and metestasis. J Pharmacol Sci. 2005;97(4):533-40.

17. Mintom C, E JIN, Taniuchi N, Matsuoka T, Yamagishi S, Ghazizadeh M, Kawanami O. Demonstration of microvessel network and endothelial cell phenotypes in the normal murine lung. J Nippon Med School 2005;76(6):314-5.

18. Schoell WM, Pieber D, Reich O, Lahousen M, Janicek M, Winter R. Tumor angiogenesis as a prognostic factor in ovarian carcinoma: Quantification of endothelial immunoreactivity by image analysis. Cancer 1997;80(12):225762.

19. Siitonen SM, Haapasalo HK, Rantala IS, Helin HJ, Isola JJ. Prognostic comparison of different immunohistochemical methods in the assessment of angiogenesis: Lack of prognostic value in a group of 77 selected node-negative 
breast carcinomas. Mod Pathol. 1995;8(7):745-52.

20. Thomazini CM, Pinheiro NA, Pardini MI, Naresse LE, Rodrigues MAM. Infecção por Helicobacter pylori e câncer gástrico: Freqüência das cepas patogênicas cagA e vacA em pacientes com câncer gástrico. J Bras Patol Med Lab 2006;42(1):1-10.

21. Van Velthoven R, Petein M, Zlotta A, Oosterlinck WJ, Van Der Eidjen A, Zandona C, Roels H, Pasteels J, Schulman C. Computer-assisted chromatin texture characterization of Feulgen-stained nuclei in a series of 331 transitional bladder cell carcinomas. J Pathol 1994;173:235-42.
22. Zhao HC, Qin R, Chen XX, Sheng X, WU JF, Wang DB, Chen GH. Microvessel density is a prognostic marker of human gstric cancer. Wourld J Gastroenterol. 2006;12(47):7598-603.

Conflito de interesse: não há Fonte financiadora: não há Recebido para publicação em: 03/05/2007 Aceito para publicação em: 09/09/2007 